\title{
The Comparison of the Functional Movement Screen Test Results of Volleyball National Team Players in Different Countries
}

\author{
Hasan Aka ${ }^{1}$, Gürkan Yılmaz ${ }^{2}$, Zait Burak Aktuğ $\breve{g}^{2}$, Cengiz Akarçeşme ${ }^{3} \&$ Emre Altundağ $^{1}$ \\ ${ }^{1}$ Ministry of Education, Ankara, Turkey \\ ${ }^{2}$ Niğde Ömer Halisdemir University, School of Physical Education and Sports, Niğde, Turkey \\ ${ }^{3}$ Gazi University, Faculty of Sport Sciences, Ankara, Turkey \\ Correspondence: Zait Burak Aktuğ, Niğde Ömer Halisdemir University, School of Physical Education and \\ Sports, Niğde, Turkey. E-mail: zaitburak@gmail.com
}

Received: October 22, 2018

Accepted: November 20, 2018 Online Published: December 30, 2018

doi:10.5539/jel.v8n1p138

URL: https://doi.org/10.5539/jel.v8n1p138

\begin{abstract}
This study was conducted to compare the functional movement patterns of female volleyball players from different countries. 34 the women's volleyball national team athletes from three different countries participated in the study; Turkey $(\mathrm{n}=9)$, Azerbaijan $(\mathrm{n}=16)$ and Kyrgyzstan $(\mathrm{n}=9)$. Functional movement screen of the athletes were determined by the Functional Movement Screen (FMS) test kit. The Kruskal-Wallis H Test was used for multiple comparisons from nonparametric tests in determining the difference between functional movement patterns of national teams. At the end of the study, it was determined that the FMS total scores of the teams were higher than 14 points which were considered as critical limits and there was no statistically significant difference between the FMS total scores of the teams $(p<0.05)$. However, there were significant differences between the teams in the hurdle step, shoulder clearing test and shoulder mobility tests which formed the FMS test battery. As a conclusion, the fact that volleyball players in each country have more than 14 points of FMS total score, which is the critical limit, shows that volleyball players have low risk of injury. This may be related to the elite level of volleyball players and the implementation of correct training models.
\end{abstract}

Keywords: functional movement screen, volleyball, elite athlete

\section{Introduction}

Volleyball is a team sport that has a wide range of spectators all around the world. Although there is no physical contact with the opponent in volleyball, sport injuries are very common. Solgard et al (1995) found that volleyball was in the fourth place in injury rate. When the injuries in volleyball are examined, it is evident that injuries on lower extremities seem to be higher (Marwan et al., 2012). Sports injuries are more common in sports branches where jumping, hopping and rapid displacements occur (Renstrom et al., 2008; Lindenfeld et al., 1994). On the basis of volleyball, such movements are more likely to increase the likelihood of injury (Solgard et al., 1995). In addition to sportive injuries, overuse injuries may occur in athletes (Kanbir, 2001).

Preventing sportive injuries in volleyball is an essential factor for both sports health and sports performance. It is very important to anticipate sports injuries and to take precautions for this situation. In recent years, the determination of the asymmetry and weak connections in the basic functional movement patterns of athletes and the FMS test are applied to determine the injury tendencies and the risk of injury. In the evaluation of the FMS test; joint motion range, movement asymmetry, body strength and stabilization, balance, neuromuscular coordination, flexibility and dynamic elasticity properties are provided by non-invasive, easy and economical detection (Cook, 2003). FMS measurements are important in order to evaluate the quality of the basic movement patterns of the athletes and reveal the stabilization and mobilization of the structures forming the movement, which is considered to be a reliable method (Cook, Burton, \& Hoogenboom, 2006; Moran, Schneiders, Major, \& Sullivan, 2016). FMS test battery can analyze the basic movements and observe the asymmetry, mobility and stability conditions of the athletes and the estimated information about the risk of injury of the athletes (Kiesel, Plisky, \& Voight, 2007).

The rehabilitation period after athletes' injuries and the measurement methods used to predict injuries are both expensive, and thus requiring necessary equipment. The FMS test battery ensures that basic movements can be 
quickly analyzed and rated without the need for expensive equipment. The aim of this study is to compare the functional movement patterns of women volleyball players from different countries and to determine the probability of encountering sports injuries.

\section{Method}

\subsection{Data Gathering Tools}

In the current study, 34 athletes participated in the women volleyball national team from Turkey, Azerbaijan and Kyrgyzstan. The athletes who participated in the study were had no any sportive injuries during the last 6 months. The tests were performed on volleyball players' off days and the athletes were asked not to participate in any sports activities during the last 24 hours prior to the tests which they were going to participate in.

\subsection{Functional Movement Screen Test}

Functional movement Screen was determined by means of the Functional Movement Screen Test Kit developed by Gray Cook (Güzel \& Kafa, 2017). The movements in this test are deep squat, hurdle step, forward lunge, shoulder mobility, active straight leg raise, push-ups push up and body rotation stability, respectively. Measurements were conducted considering the basal status of their bodies without any warm-up. Before the athletes started the measurements, the athlete was informed of the test by the expert who performed the test in detail. Each movement was repeated three times during the test. The subjects were asked to state pain or discomfort during the implementation of the movements. In the test, unilateral motions (deep squat, push-up test) were measured. In the two-sided tests; (hurdle step, in line lunge, shoulder mobility, active leg raiser, rotator stability balance), left and right scoring were performed separately.

During the scoring, the scores of the participants in both directions were recorded. However, the lowest score obtained from the test was accepted as a definite result. For example; in the obstacle step (hurdle step), the athlete, whose left leg score was 1 and the right leg score as 2, had the score 1 . This procedure was applied for bilateral movements. Each test was given a score between 0 and 3. The highest FMS test score is 21 (Cook, Burton, Kiesel, Bryant, \& Torine, 2010). Individuals with a total FMS score lower than 14 points have a higher risk of injury than those having the total score higher than 14 (Kiesel, Plisky, \& Voight, 2007).

\subsection{Data Analysis}

Statistical analysis of the obtained data was conducted through SPSS 22.0 package program. The normality test was performed in order to determine whether the data were within normal distribution. In the current study, total number of players in the teams was 34: Turkey $(n=9)$, Azerbaijan $(n=16)$ and Kyrgyzstan $(n=9)$. Shapiro-Wilk table was examined since the number of athletes $(16,9$ and 9$)$ belonging to the individual countries examined was below 30. According to Shapiro-Wilk table, the variables were normal $(\mathrm{p}<0.05)$. Therefore, Kruskal-Wallis $\mathrm{H}$ Test was applied to the variables for multiple comparisons from nonparametric tests.

\section{Results}

Table 1. Demographic data of the participants

\begin{tabular}{lllll}
\hline Groups & & $\mathrm{N}$ & Mean & $\mathrm{Sd}$ \\
\hline Azerbaijan & Age (year) & 16 & 16.43 & 1.26 \\
& Height (cm) & 16 & 172.75 & 6.16 \\
& Body Weight (kg) & 16 & 60.12 & 5.53 \\
Kirgizstan & Age (year) & 9 & 20.55 & 2.4 \\
& Height (cm) & 9 & 169.66 & 6.18 \\
& Body Weight (kg) & 9 & 59.44 & 5.02 \\
Turkey & Age (year) & 9 & 21.66 & 2.73 \\
& Height (cm) & 9 & 185.66 & 4.58 \\
& Body Weight (kg) & 9 & 70.55 & 3.94 \\
\hline
\end{tabular}


Table 2. Functional Movement Screen Values of the Athletes

\begin{tabular}{|c|c|c|c|c|c|c|}
\hline & Groups & $\mathrm{N}$ & Mean \pm Sd & Sequence Mean & $\mathrm{X}^{2}$ & $\mathrm{p}$ \\
\hline \multirow[t]{3}{*}{ Deep Squat } & Azerbaijan & 16 & $1.93 \pm 0.68$ & 16.19 & 1.347 & .510 \\
\hline & Kirgizstan & 9 & $2.11 \pm 0.33$ & 17.78 & & \\
\hline & Turkey & 9 & $2.22 \pm 0.44$ & 19.56 & & \\
\hline \multirow[t]{3}{*}{ Hurdle Step Left } & Azerbaijan & 16 & $1.62 \pm 0.61$ & $13.38^{\mathrm{ab}}$ & 10.311 & $.006^{* *}$ \\
\hline & Kirgizstan & 9 & $1.88 \pm 0.60$ & $16.89^{\mathrm{b}}$ & & \\
\hline & Turkey & 9 & $2.55 \pm 0.52$ & $25.44^{\mathrm{cb}}$ & & \\
\hline \multirow[t]{3}{*}{ Hurdle Step Right } & Azerbaijan & 16 & $1.81 \pm 0.54$ & $13.66^{\mathrm{ab}}$ & 8.401 & $.015^{*}$ \\
\hline & Kirgizstan & 9 & $2.11 \pm 0.60$ & $17.78^{\mathrm{b}}$ & & \\
\hline & Turkey & 9 & $2.55 \pm 0.52$ & $24.06^{\mathrm{cb}}$ & & \\
\hline \multirow[t]{3}{*}{ Hurdle Step Total } & Azerbaijan & 16 & $1.43 \pm 0.51$ & $13.06^{\mathrm{ab}}$ & 10.556 & $.005^{* *}$ \\
\hline & Kirgizstan & 9 & $1.77 \pm 0.66$ & $17.72^{\mathrm{b}}$ & & \\
\hline & Turkey & 9 & $2.33 \pm 0.50$ & $25.17^{\mathrm{cb}}$ & & \\
\hline \multirow[t]{3}{*}{ In line Lunge Left } & Azerbaijan & 16 & $2.43 \pm 0.51$ & 15.94 & 1.211 & .546 \\
\hline & Kirgizstan & 9 & $2.55 \pm 0.52$ & 17.94 & & \\
\hline & Turkey & 9 & $2.66 \pm 0.50$ & 19.83 & & \\
\hline \multirow[t]{3}{*}{ In line Lunge Right } & Azerbaijan & 16 & $2.06 \pm 0.77$ & 14.69 & 3.075 & .215 \\
\hline & Kirgizstan & 9 & $2.44 \pm 0.52$ & 19.17 & & \\
\hline & Turkey & 9 & $2.55 \pm 0.52$ & 20.83 & & \\
\hline \multirow[t]{3}{*}{ In line Lunge Total } & Azerbaijan & 16 & $2.06 \pm 0.77$ & 15.44 & 1.763 & .414 \\
\hline & Kirgizstan & 9 & $2.33 \pm 0.50$ & 18.50 & & \\
\hline & Turkey & 9 & $2.44 \pm 0.50$ & 20.17 & & \\
\hline \multirow[t]{3}{*}{ Shoulder Mobility Left } & Azerbaijan & 16 & $2.62 \pm 0.50$ & 18.50 & 4.932 & .085 \\
\hline & Kirgizstan & 9 & $2.77 \pm 0.44$ & 20.94 & & \\
\hline & Turkey & 9 & $2.11 \pm 0.78$ & 12.28 & & \\
\hline \multirow[t]{3}{*}{ Shoulder Mobility Right } & Azerbaijan & 16 & $3.00 \pm 0.00$ & 19.00 & 3.509 & .173 \\
\hline & Kirgizstan & 9 & $2.88 \pm 0.33$ & 17.11 & & \\
\hline & Turkey & 9 & $2.77 \pm 0.44$ & 15.22 & & \\
\hline \multirow[t]{3}{*}{ Shoulder Clearing Test } & Azerbaijan & 16 & $0.12 \pm 0.34$ & $14.56^{\mathrm{ab}}$ & 15.840 & $.000^{* * *}$ \\
\hline & Kirgizstan & 8 & $0.00 \pm 0.00$ & $12.50^{\mathrm{b}}$ & & \\
\hline & Turkey & 9 & $0.77 \pm 044$ & $25.33^{\mathrm{c}}$ & & \\
\hline \multirow[t]{3}{*}{ Shoulder Mobility Total } & Azerbaijan & 16 & $2.37 \pm 1.02$ & $20.25^{\mathrm{ab}}$ & 17.071 & $.000^{* * *}$ \\
\hline & Kirgizstan & 9 & $2.77 \pm 0.44$ & $23.22^{\mathrm{b}}$ & & \\
\hline & Turkey & 9 & $0.44 \pm 0.88$ & $6.89^{\mathrm{c}}$ & & \\
\hline \multirow[t]{3}{*}{ Active Leg Raise Left } & Azerbaijan & 16 & $2.43 \pm 0.51$ & 15.94 & 2.943 & .230 \\
\hline & Kirgizstan & 9 & $2.44 \pm 0.52$ & 16.06 & & \\
\hline & Turkey & 9 & $2.77 \pm 0.44$ & 21.72 & & \\
\hline \multirow{3}{*}{ Active Leg Raise Right } & Azerbaijan & 16 & $2.43 \pm 0.51$ & 14.94 & 4.755 & .093 \\
\hline & Kirgizstan & 9 & $2.55 \pm 0.52$ & 16.94 & & \\
\hline & Turkey & 9 & $2.88 \pm 0.33$ & 22.61 & & \\
\hline \multirow[t]{3}{*}{ Active Leg Raise Total } & Azerbaijan & 16 & $2.43 \pm 2.51$ & 16.22 & 3.070 & .215 \\
\hline & Kirgizstan & 9 & $2.22 \pm 0.97$ & 15.44 & & \\
\hline & Turkey & 9 & $2.77 \pm 0.44$ & 21.83 & & \\
\hline Trunk Stability Push up & Azerbaijan & 16 & $2.06 \pm 0.99$ & 15.13 & 2.121 & .346 \\
\hline & Kirgizstan & 9 & $2.55 \pm 0.52$ & 19.61 & & \\
\hline & Turkey & 9 & $2.55 \pm 0.52$ & 19.61 & & \\
\hline Trunk Clearing Test & Azerbaijan & 16 & $0.18 \pm 0.40$ & 18.59 & 3.400 & .183 \\
\hline & Kirgizstan & 8 & $0.00 \pm 0.00$ & 15.50 & & \\
\hline & Turkey & 9 & $0.00 \pm 0.00$ & 15.50 & & \\
\hline Rotator Stability Left & Azerbaijan & 16 & $2.00 \pm 0.36$ & 17.50 & 0.000 & 1.000 \\
\hline & Kirgizstan & 9 & $2.00 \pm 0.00$ & 17.50 & & \\
\hline & Turkey & 9 & $2.00 \pm 0.00$ & 17.50 & & \\
\hline Rotator Stability Right & Azerbaijan & 16 & $1.93 \pm 0.25$ & 16.94 & 1.125 & .570 \\
\hline & Kirgizstan & 9 & $2.00 \pm 0.00$ & 18.00 & & \\
\hline & Turkey & 9 & $2.00 \pm 0.00$ & 18.00 & & \\
\hline Rotator Stability Clearing Test & Azerbaijan & 16 & $0.00 \pm 0.00$ & 17.50 & 0.000 & 1.000 \\
\hline & Kirgizstan & 9 & $0.00 \pm 0.00$ & 17.50 & & \\
\hline & Turkey & 9 & $0.00 \pm 0.00$ & 17.50 & & \\
\hline Rotator Stability Total & Azerbaijan & 16 & $1.93 \pm 0.25$ & 16.94 & 1.125 & .570 \\
\hline & Kirgizstan & 9 & $2.00 \pm 0.00$ & 18.00 & & \\
\hline & Turkey & 9 & $2.00 \pm 0.00$ & 18.00 & & \\
\hline Total score & Azerbaijan & 16 & $14.25 \pm 2.46$ & 15.94 & 2.991 & .224 \\
\hline & Kirgizstan & 9 & $15.77 \pm 1.39$ & 22.33 & & \\
\hline & Turkey & 9 & $14.77 \pm 2.22$ & 15.44 & & \\
\hline
\end{tabular}


There is no difference between the groups bearing the same letter in the same column.

There is a difference between groups with different letters in the same column.

Hurdle step left between Azerbaijan and Turkey, $004(* * \mathrm{p}<0.01)$ significant difference in the level was determined in favor of Turkey.

Hurdle step right between Azerbaijan and Turkey, $011(* * \mathrm{p}<0.05)$ significant difference in the level was determined in favor of Turkey.

Hurdle step total between Azerbaijan and Turkey, $003(* * p<0.01)$ significant difference in the level was determined in favor of Turkey.

Shoulder clearing test between Kyrgyzstan and Turkey, $001\left({ }^{* *} \mathrm{p}<0.01\right)$ a significant difference in the level were determined in favor of Turkey.

Shoulder clearing test between Azerbaijan and Turkey, $002(* * \mathrm{p}<0.01)$ a significant difference in the level was determined in favor of Turkey.

Shoulder mobility total between Azerbaijan and Turkey, $000(* * * \mathrm{p}<0.001)$, a significant difference was determined in favor of Azerbaijan at the level.

Shoulder mobility total between Kyrgyzstan and Turkey, $000(* * * \mathrm{p}<0.001)$ a significant differences was in the level was determined in favor of Kyrgyzstan.

\section{Discussion}

The purpose of this study was to compare the tests results of the functional movement screen of volleyball players from different countries at the national team level. Within the scope of the research, the FMS results of Turkey, Azerbaijan and Kyrgyzstan women's volleyball national teams were evaluated and it was evident their scores had very close rates. According to these results, it can be stated that the FMS total score of the athletes in the subjects group is higher than 14 points, which is considered as critical limits. In addition, the FMS scores of the athletes in national teams with higher than 14 points can be considered as a low risk of injury and good joint mobility. As a matter of fact, when compared with those having the score higher than 14, those having the score lower than 14 had the risk of injury by $17.7 \%$ (Kiesel, Plisky, \& Voight, 2007). Hurdle step which is one of the FMS sub-tests is a one-sided movement that requires the athlete to stabilize one leg and mobilize the other leg (Kiesel, Plisky, \& Voight, 2007). As a result of athletes' hurdle step test (left-right leg and total) between the national teams of Azerbaijan and Turkey, it was identified that there was a significant difference, which was in favor of Turkey. According to the results of Turkey's national team athletes, it was considered that the hip flexor muscles were in more active use. When athletes' shoulder clearing test values were examined, it was evident that Turkey's values were significantly higher than those of Azerbaijan and Kyrgyzstan national teams. Clearing test results are one of the sub-tests of FMS which reveals the pain level of athletes (Güzel \& Kafa 2017). Thus, it can be stated that the athletes in the national team of Turkey has the high pain levels. These results may stem from the fact that the national team of Turkey had more matches and training sessins; therefore, the athletes were to use the upper extremities more.

When the test results of shoulder mobility test results were analyzed the values of both Azerbaijan and Kyrgyzstan were significantly higher than those of Turkey. In this case, it can be considered that the risk of injury on the shoulder joint of the athletes in Azerbaijan and Kyrgyzstan national team was lower than those in Turkey. Shoulder mobility requires mobility of the shoulder girdle, shoulder joint and thoracic spine. In this test, the mobility of both arms is measured (Cook Burton, Kiesel, Rose, \& Bryant, 2010). Mobility differences between the right and left shoulder should increase the risk of injury in athletes. Considering this situation, it can be said that the coach and athletes should focus on the differences between the right and left shoulder mobility (Mulligan, Biddington, Barnhart, \& Ellenbecker, 2004).

As a conclusion, FMS provides coaches and athletes with valuable knowledge about the risk of injury. In some studies conducted in the current literature, although there was no significant relationship between FMS and athletic performance (Altundağ, 2018; Lloyd et al., 2015; Lockie et al., 2015), the risk of athletes' injury was determined in advance and the elimination of these factors could be longer than the athletes and thus increasing the athletic performance indirectly. It can be considered when athletes are trained with the correct movement patterns at a young age, there seems to be certain advantages, which can contribute to correct movement patterns. 


\section{References}

Altundağ, E. (2018). Elit Bayan Voleybolcularda fonksiyonel hareket taraması test skorları ile atletik performans arasındaki ilişkinin araştırılması. Yüksek Lisans Tezi, Bolu Abant İzzet Baysal Üniversitesi, Sağllk Bilimleri Enstitüsü, Bolu.

Cook, G. (2003). Athletic body in balance. USA: Human Kinetics.

Cook, G., Burton, L., \& Hoogenboom, B. (2006). Pre-participation screening: the use of fundamental movements as an assessment of function - part 1. North American Journal of Sports Physical Therapy, 1(2), 62-72.

Cook, G., Burton, L., Kiesel, K., Rose, G., \& Bryant, M. F. (2010). Movement: functional movement systems: screening, assessment, and corrective strategies. On Target Publications Aptos, CA.

Güzel, N., \& Kafa, N. (2017). Sporcu sağllğg. Sözkesen matbaacılık, Ankara, s.70-72.

Kanbir, O. (2001). Sporda Sağllk Bilinci ve İlkyardım. Etkin kitapevi, Bursa.

Kiesel, K., Plisky, P. J., \& Voight, M. L. (2007). Can serious injury in professional football be predicted by a preseason functional movement screen? North American Journal of Sports Physical Therapy, 2(3), 147-158.

Lindenfeld, T. N., Schmitt, D. J., Hendy, M. P., Mangine, R. E., \& Noyes, F. R. (1994). Incidence of injury in indoor soccer. The American Journal of Sports Medicine, 22(3), 364-371. https://doi.org/10.1177/036354659402200312

Lloyd, R. S., Oliver, J. L., Radnor, J. M., Rhodes, B. C., Faigenbaum, A. D., \& Myer, G. D. (2015). Relationships between functional movement screen scores, maturation and physical performance in young soccer players. Journal of Sports Sciences, 33(1), 11-19. https://doi.org/10.1080/02640414.2014.918642

Lockie, R. G., Schultz, A. B., Callaghan, S. J., Jordan, C. A., Luczo, T. M., \& Jeffriess, M. D. (2015). A preliminary investigation into the relationship between functional movement screen scores and athletic physical performance in female team sport athletes. Biology of Sport, 32(1), 41-45. https://doi.org/10.5604/20831862.1127281

Marwan, Y., Behbehani, A., Al-Mousawi, A., Mulla-Juma'a, A., Sadeq, H., \& Shah, N. (2012). Sports Injuries among professional male athletes in Kuwait: prevalence and associated factors. Medical Principles and Practise. 21(2), 171-177. https://doi.org/10.1159/000332442

Moran, R. W., Schneiders, A. G., Major, K. M., \& Sullivan, S. J. (2016). How Reliable are functional movement screening scores. a systematic review of rater reliability. British Journal of Sports Medicine, 50(9), 527-536. https://doi.org/10.1136/bjsports-2015-094913

Mulligan, I. J., Biddington, W. B., Barnhart, B. D., \& Ellenbecker, T. S. (2004). Isokinetic profile of shoulder internal and external rotators of high school aged baseball pitchers. Journal of Strength \& Conditioning Research, 18(4), 861-866.

Renstrom, P., Ljungqvist, A., Arendt, E., Beynnon, B., Fukubayashi, T., Garrett, W., \& Engebretsen, L. (2008). Non-contact ACL injuries in female athletes: An International Olympic Committee current concepts statement. British Journal of Sports Medicine, 42(6), 394-412. https://doi.org/10.1136/bjsm.2008.048934

Solgard, L., Buhl Nielsen, A., Mdler-Madsen, B., Wulff Jacobsen, B., Yde, J., \& Jensen, J. (1995). Volleyball injuries presenting in casualty. A prospective study. British Journal of Sports Medicine, 29(3), 200-204. https://doi.org/10.1136/bjsm.29.3.200

\section{Copyrights}

Copyright for this article is retained by the author(s), with first publication rights granted to the journal. This is an open-access article distributed under the terms and conditions of the Creative Commons Attribution license (http://creativecommons.org/licenses/by/4.0/). 